\title{
Canadian Thoracic Society Asthma Management Continuum - 2010 Consensus Summary for children six years of age and over, and adults
}

\author{
M Diane Lougheed MD MSc${ }^{1}$, Chair; Catherine Lemière $M D^{2}$, Sharon D Dell MD ${ }^{3}$, Francine $M$ Ducharme $M D^{4}$,

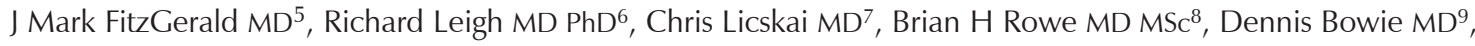 \\ Allan Becker MD ${ }^{10}$, Louis-Philippe Boulet $\mathrm{MD}^{11}$
}

\begin{abstract}
MD Lougheed, C Lemière, SD Dell, et al. Canadian Thoracic Society Asthma Management Continuum - 2010 Consensus Summary for children six years of age and over, and adults. Can Respir J 2010;17(1):15-24.
\end{abstract}

BACKGROUND/OBJECTIVE: To integrate new evidence into the Canadian Asthma Management Continuum diagram, encompassing both pediatric and adult asthma.

METHODS: The Canadian Thoracic Society Asthma Committee members, comprised of experts in pediatric and adult respirology, allergy and immunology, emergency medicine, general pediatrics, family medicine, pharmacoepidemiology and evidence-based medicine, updated the continuum diagram, based primarily on the 2008 Global Initiative for Asthma guidelines, and performed a focused review of literature pertaining to key aspects of asthma diagnosis and management in children six years of age and over, and adults.

RESULTS: In patients six years of age and over, management of asthma begins with establishing an accurate diagnosis, typically by supplementing medical history with objective measures of lung function. All patients and caregivers should receive self-management education, including a written action plan. Inhaled corticosteroids (ICS) remain the first-line controller therapy for all ages. When asthma is not controlled with a low dose of ICS, the literature supports the addition of long-acting beta 2 -agonists in adults, while the preferred approach in children is to increase the dose of ICS. Leukotriene receptor antagonists are acceptable as second-line monotherapy and as an alternative add-on therapy in both age groups. Antiimmunoglobulin E therapy may be of benefit in adults, and in children 12 years of age and over with difficult to control allergic asthma, despite high-dose ICS and at least one other controller.

CONCLUSIONS: The foundation of asthma management is establishing an accurate diagnosis based on objective measures (eg, spirometry) in individuals six years of age and over. Emphasis is placed on the similarities and differences between pediatric and adult asthma management approaches to achieve asthma control.

Key Words: Asthma; Guidelines; Management
Le continuum de prise en charge de l'asthme de la Société canadienne de thoracologie - Sommaire consensuel 2010 pour les enfants de six ans et plus et les adultes

HISTORIQUE ET OBJECTIF : Intégrer les nouvelles données probantes au diagramme du continuum canadien de prise en charge de l'asthme, englobant l'asthme à la fois chez les enfants et chez les adultes.

MÉTHODOLOGIE : Les membres du comité sur l'asthme de la Société canadienne de thoracologie, composé d'experts en respirologie, en allergie et en immunologie chez les adultes et les enfants, en médecine d'urgence, en pédiatrie générale, en médecine de famille, en pharmacoépidémiologie et en médecine probante. Ils ont mis à jour le diagramme du continuum fondé principalement sur les lignes directrices de l'initiative mondiale 2008 sur l'asthme et procédé à une analyse bibliographique ciblée sur les principaux aspects du diagnostic et de la prise en charge de l'asthme chez les enfants de six ans et plus et les adultes.

RÉSULTATS : Chez les patients de six ans et plus, la prise en charge de l'asthme commence par un diagnostic précis, généralement en complétant les antécédents médicaux de mesures objectives de la fonction pulmonaire. Tous les patients et les soignants devraient être informés des modes d'autogestion, y compris un plan d'action écrit. Les corticoïdes en aérosol (CEA) demeurent le traitement de contrôle de première ligne à tout âge. Lorsque l'asthme ne se contrôle pas au moyen d'une faible dose de CEA, les publications étayent l'ajout d'un bêta 2 -agoniste de longue durée chez les adultes, tandis que, chez les enfants, on favorise l'accroissement de la dose de CEA. Les antagonistes des récepteurs des leucotriènes sont acceptables comme monothérapie de deuxième ligne et comme autre traitement d'appoint dans les deux groupes d'âge. La thérapie à l'antiimmunoglobuline E peut être bénéfique aux adultes ainsi qu'aux enfants de 12 ans et plus éprouvant de la difficulté à contrôler l'asthme allergique malgré de forte doses de CEA et au moins un autre traitement de contrôle. CONCLUSIONS : Les assises de la prise en charge de l'asthme consistent à poser un diagnostic exact fondé sur des mesures objectives (p. ex., spirométrie) chez les personnes de six ans et plus. On s'attarde sur les similarités et les différences entre les démarches de prise en charge de l'asthme chez les enfants et chez les adultes afin de contrôler l'asthme.

of existing guidelines. The CTS Asthma Committee will follow the ADAPTE process (www.adapte.org) to conduct a detailed update of the 2003 Canadian Asthma Consensus Guidelines, beginning in the spring of 2010, focusing primarily on published international and national guidelines (3-5) and new literature. Recognizing this as a lengthy, formal process, the Asthma Committee identified the need for an updated comprehensive management continuum diagram encompassing asthma management for Canadians of all ages. The complexities and atric (2) asthma was during a 2003 consensus conference. Since that revision, new scientific evidence regarding asthma epidemiology, pathophysiology and pharmacotherapy has been published.

The Canadian Thoracic Society (CTS) Respiratory Guidelines Committee has established formal processes for the development of new guidelines and the revision or adaptation
${ }^{1}$ Queen's University, Kingston, Ontario; ${ }^{2}$ University of Montreal, Montreal, Quebec; ${ }^{3}$ University of Toronto, Toronto, Ontario; ${ }^{4}$ University of
Montreal, Montreal, Quebec; ${ }^{5}$ University of British Columbia, Vancouver, British Columbia; ${ }^{6}$ University of Calgary, Calgary, Alberta;
${ }^{7}$ University of Western Ontario, London, Ontario; ${ }^{8}$ University of Alberta, Edmonton, Alberta; ${ }^{9}$ Dalhousie University, Halifax, Nova Scotia;
${ }^{10}$ University of Manitoba, Winnipeg, Manitoba; ${ }^{11}$ Laval University, Quebec City, Quebec
Correspondence: Dr M Diane Lougheed, Division of Respirology, Department of Medicine, Queen's University, 102 Stuart Street, Kingston,
Ontario K7L 2V6. Telephone 613-548-2348, fax 613-549-1459, e-mail mdl@queensu.ca
Reprints: Ms Lise Dingwell, Administrative Coordinator, The Canadian Thoracic Society. Telephone 613-569-6411 ext 270, e-mail infocts@lung.ca 
unique aspects of the assessment and management of asthma in preschool-age children proved too challenging to address within the same document. Pending development of a CTS guideline for asthma in children five years of age and younger, the committee endorses application of the Global Initiative for Asthma (6) guidelines for the diagnosis and management of asthma in this age group. The present document summarizes the management of individuals six years of age and over in one continuum diagram, which is considered to be a key knowledge translation tool for all providers.

\section{METHODS}

The Committee members were assigned specific components of the asthma management continuum to update. Members reviewed these topics within the 2003 Canadian guidelines (1,2), the Global Initiative for Asthma guidelines (5), the British Thoracic Society and Scottish Intercollegiate Guidelines Network Guidelines (4), the National Institutes of Health National Heart, Lung and Blood Institute Expert Panel Report 3 (3) and new literature, and adapted these to the Canadian context. Submissions on each topic were further reviewed and revised by the Committee, and incorporated into an illustrative continuum diagram pertaining to children six years of age and over, and adults. The updated continuum diagram and accompanying summary, which encompasses both adult and pediatric asthma highlighting important and new issues for Canadians, were approved by the CTS Executive for publication and dissemination.

\section{THE 2010 ASTHMA MANAGEMENT CONTINUUM}

The revised continuum diagram illustrates the most important key messages regarding asthma diagnosis and management for children (six years of age and over) and adults (Figure 1). It has been modified from previous versions to reflect the importance of ensuring that the diagnosis is confirmed with objective assessment of lung function, regular reassessment of spirometry or peak expiratory flow (PEF) in monitoring asthma control, and to highlight the similarities and differences between the management of children and adults. The focus of the present Consensus Summary is to provide a concise overview of comprehensive asthma care for children (six years of age and over) and adults, and highlight new evidence supporting the key messages illustrated in the revised continuum diagram.

\section{DIAGNOSIS}

A diagnosis of asthma should be considered in individuals of all age groups with recurrent symptoms (eg, frequent episodes of breathlessness, chest tightness, wheezing or cough, that are often worse at night and in the early morning) and signs of variable airway obstruction. These symptoms often develop in conjunction with viral respiratory tract infections, or after exercise or exposure to aeroallergens or irritants, and improve in response to bronchodilator or anti-inflammatory therapy. Although classically the symptoms of asthma are episodic, the disease is not. Symptoms may also be persistent in both children and adults. Signs of severe airflow obstruction include wheezing, tachypnea, decreased breath sound intensity, accessory muscle use, and intercostal or supraclavicular indrawing, and nasal flaring. Symptoms and signs of airway obstruction and response to therapy are suggestive of a diagnosis of asthma.
Clinical suspicion of asthma should be confirmed by objective measures of pulmonary function showing reversible airway obstruction (after a bronchodilator), variable airflow limitation over time or airway hyper-responsiveness in all patients able to reproducibly undergo lung function testing.

Canadian research (7) highlighted the need for lung function testing to confirm the presence of reversible airway obstruction, best accomplished by pre- and postbronchodilator spirometry. Spirometry is the measurement of flow rates and volumes during a forced expiratory manoeuvre to determine the forced expiratory volume in $1 \mathrm{~s}\left(\mathrm{FEV}_{1}\right)$ and the forced vital capacity (FVC). The ratio $\mathrm{FEV}_{1} / \mathrm{FVC}$ is a measure of airflow obstruction. Such tests must be performed by standardized methods, as described by the European and American Thoracic Societies (8). Most children six years of age and over are able to undergo spirometry. The diagnosis of asthma is supported when reversible airflow obstruction is present. Table 1 outlines pulmonary function criteria for children and adults using the preferred diagnostic test (spirometry), and alternatives such as PEF monitoring (9) and challenge tests. Many patients with controlled asthma will not exhibit airflow obstruction or this degree of postbronchodilator reversibility at each assessment. To increase sensitivity, spirometry should be repeated, particularly during symptoms. Measurements of airway responsiveness to methacholine, histamine or exercise may be useful in diagnostic dilemmas, such as individuals with persistent asthma symptoms despite normal spirometry, and to evaluate workrelated asthma. However, methacholine challenge testing is not necessary if reversible airflow obstruction is demonstrated, and is contraindicated if the $\mathrm{FEV}_{1}$ is below $60 \%$ predicted. A trial of therapy is acceptable to confirm a clinical diagnosis, particularly in young children and when methacholine challenge testing is not feasible.

Chest radiographs are not routinely required to diagnose asthma, but may be useful to exclude other diagnoses in children (eg, congenital malformations) and adults (eg, congestive heart failure). Measurements of airway inflammation are not yet widely available for the diagnosis of asthma.

\section{ASTHMA CONTROL}

The primary goal of asthma management is to control the disease and, by doing so, prevent or minimize the risk of shortand long-term complications, morbidity and mortality. The concept of asthma control, introduced in the 1996 Canadian guidelines (10), has become the global standard for monitoring the adequacy of asthma management $(9,11)$, which should be assessed at each clinical encounter. National and international guidelines have differed with respect to the frequencies or values of each characteristic deemed 'acceptable'. Increasingly, more stringent symptom criteria and lenient spirometric criteria have become the therapeutic target. In the absence of substantive evidence to support the incremental benefit of these revisions, the existing Canadian criteria remain appropriate (Table 2). Regular need for a reliever to prevent or treat exercise-induced symptoms indicates suboptimal control and should be included in the weekly limit. Such individuals may need escalation of controller therapy. An acute care visit (eg, walk-in clinic, emergency department or hospitalization) should be considered a management failure, and prompt the review of maintenance therapy and factors contributing to poor control. 


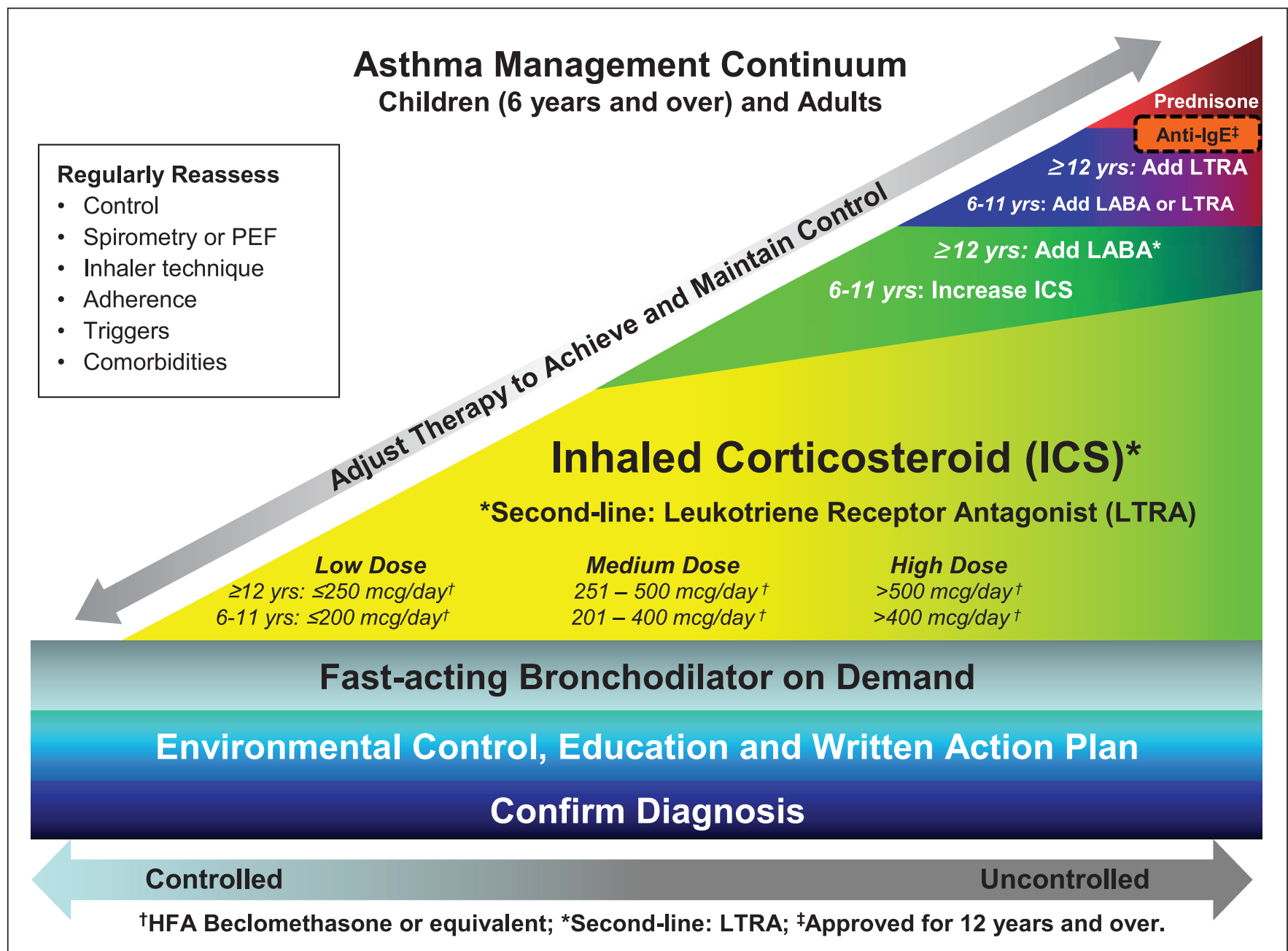

Figure 1) Very mild, intermittent asthma may be treated with fast-acting beta ${ }_{2}$-agonists taken as needed. Inhaled corticosteroids (ICS) should be introduced early as the initial maintenance treatment for asthma, even in individuals who report asthma symptoms less than three times a week. Leukotriene receptor antagonists (LTRAs) are second-line monotherapy for mild asthma. If asthma is not adequately controlled by low doses of ICS, additional therapy should be considered. In children six to 11 years of age, the ICS should be increased to a moderate dose before an additional agent such as a long-acting beta ${ }_{2}$-agonist (LABA) or LTRA is added. In children 12 years of age and over, and adults, a LABA should be considered first as add-on therapy only in combination with an ICS. Increasing to a moderate dose of ICS or addition of a LTRA are third-line therapeutic options. Theophylline may be considered as a fourth-line agent in adults. Severely uncontrolled asthma may require additional treatment with prednisone. Omalizumab may be considered in individuals 12 years of age and over with poorly controlled atopic asthma despite high doses of ICS and appropriate add-on therapy, with or without prednisone. Asthma symptom control and lung function tests, inhaler technique, adherence to asthma treatment, exposure to asthma triggers in the environment and the presence of comorbidities should be reassessed at each visit and before altering the maintenance therapy. After achieving proper asthma control for at least a few weeks to months, the medication should be reduced to the minimum necessary to achieve adequate asthma control. HFA Hydrofluoroalkane; IgE Immunoglobulin E; mcg Micrograms; PEF Peak expiratory flow; yrs Years

\section{ENVIRONMENTAL CONTROL, SELF-MANAGEMENT EDUCATION AND WRITTEN ACTION PLANS}

Environmental control

Environmental factors play an important role in the origin and persistence of asthma, severity of airflow obstruction and the ability to achieve adequate asthma control. Viral infections and other 'triggers' should be avoided whenever possible. Approximately $25 \%$ of adult asthma cases are estimated to be work related (12). Furthermore, $10 \%$ to $15 \%$ of adult asthma may be caused by an occupational agent $(13,14)$. Therefore, it is crucial to identify work-related asthma by completing a thorough medical and occupational history, and performing the appropriate investigations (15).

Primary prevention measures are not addressed in the present summary. Avoidance of irritant and allergic triggers in the home, school and/or work environments are important secondary prevention measures that should be implemented in 
TABLE 1

Diagnosis of asthma: Pulmonary function criteria

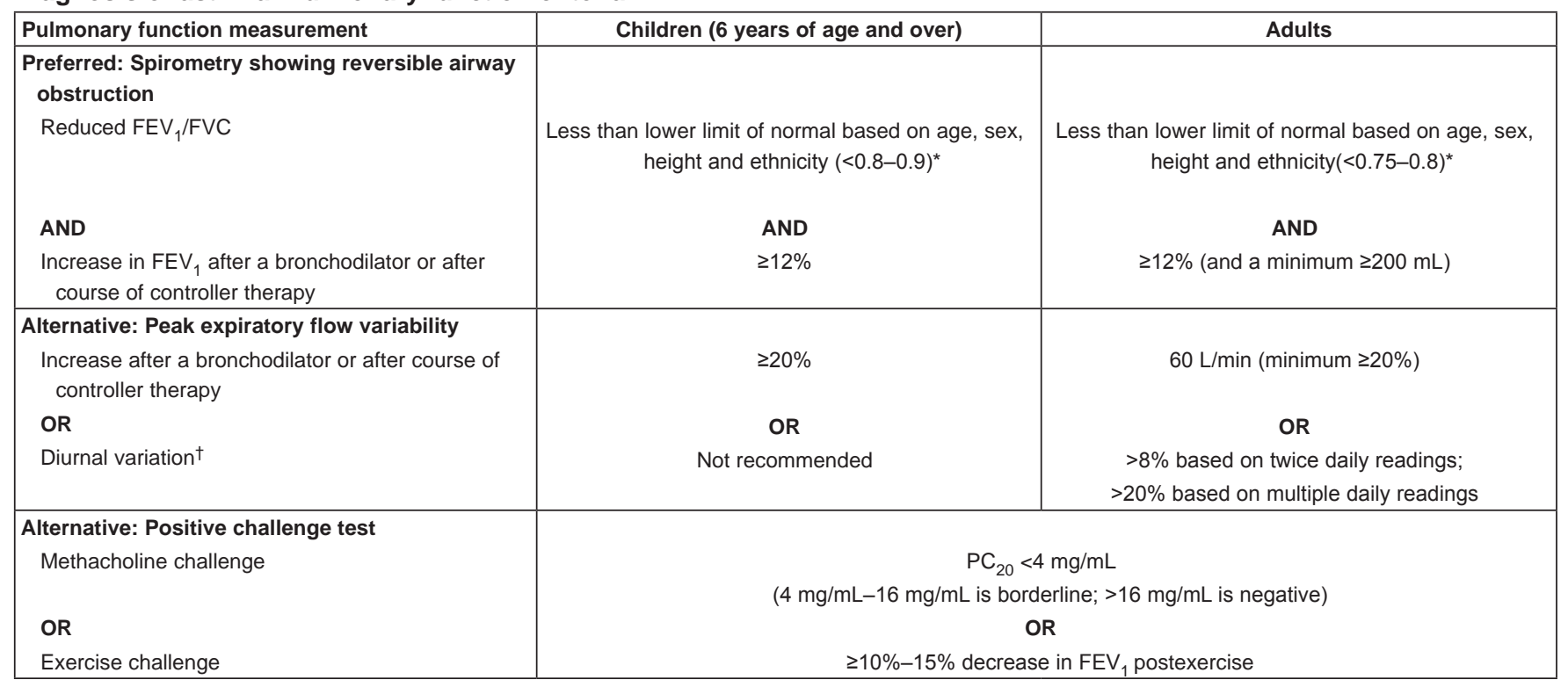

${ }^{*}$ Approximate lower limits of normal ratios for children and adults; ${ }^{\dagger}$ Difference between minimum morning prebronchodilator value in 1 week and maximum nighttime value as $\%$ of recent maximum. FEV ${ }_{1}$ Forced expiratory volume in $1 \mathrm{~s}$; FVC Forced vital capacity; $P C_{20}$ Provocative concentration of methacholine producing a $20 \%$ fall in FEV $V_{1}$.

\section{TABLE 2}

\section{Asthma control criteria}

\begin{tabular}{ll}
\hline Characteristic & Frequency or value \\
\hline Daytime symptoms & $<4$ days/week \\
Nighttime symptoms & $<1$ night/week \\
Physical activity & Normal \\
Exacerbations & Mild, infrequent \\
Absence from work or school due to asthma & None \\
Need for a fast-acting beta ${ }_{2}$-agonist & $<4$ doses/week \\
FEV 1 or PEF & $\geq 90 \%$ personal best \\
PEF diurnal variation* & $<10 \%$ to $15 \%$ \\
\hline
\end{tabular}

*Diurnal variation is calculated as the highest peak expiratory flow (PEF) minus the lowest PEF divided by the highest PEF multiplied by 100 for morning and night (determined over a two-week period). FEV 1 Forced expiratory volume in $1 \mathrm{~s}$.

managing asthma patients. While various interventions have been shown to reduce exposure to indoor allergens, the clinical benefit is somewhat controversial. Compared with single-item exposure reductions $(16,17)$, evidence is strongest for multifaceted, environmental exposure reduction interventions; however, the cost-benefit ratio of complex interventions is such that additional research is warranted.

Once an individual is sensitized to a pet, avoidance is recommended because continued exposure is associated with worsening airway inflammation and deterioration in asthma control. Studies of bathing the pet and/or use of high-efficiency particulate air filter systems have not demonstrated substantial clinical benefit (18).

Environmental tobacco smoke remains a major factor in triggering asthma in children and adults. Children with parents who smoke have a much greater incidence of respiratory infections which, in turn, also exacerbate asthma. At each clinical visit, parents should be encouraged to cease smoking in the home and other enclosed spaces such as automobiles. Smoking cessation should be strongly advised because active smoking increases asthma symptoms, accelerates the loss of lung function and reduces the efficacy of inhaled corticosteroids (ICS) and oral corticosteroids $(19,20)$.

Exposure to air pollution has been associated with increased morbidity and mortality in individuals with asthma. Recent Canadian data $(21,22)$ demonstrated an increase in emergency department and ambulatory visits due to asthma in adults and children following exposure to environmental air pollutants, specifically, ozone and particulate matter. Efforts to reduce exposure of patients with asthma to air pollution should continue.

Self-management asthma education and written action plan: Asthma education is an essential component of asthma management for all patients. Guided self-management, combining asthma education, regular medical review, self-assessment and a written action plan have been shown to reduce hospitalizations, emergency visits, urgent physician visits, missed days at work or school, days of restricted activity, and improved pulmonary function in children and in adults. Key components of an asthma educational program are outlined in Table 3.

Written action plans are a key component of care for all patients with asthma. In contrast to verbal action plans, which have not been shown to be of benefit, written action plans are highly effective therapeutic tools, particularly when combined with asthma education, self-monitoring and regular review (23). The evidence of effectiveness is strong for adults $(24,25)$ and emerging for children (26). Several preformatted written action plans are available in Canada that typically use traffic light colours to identify the level of asthma control. Action plans should outline recommended daily preventive management strategies to maintain control, when and how to adjust reliever and controller therapy for loss of control, and provide clear instructions regarding when to seek urgent medical attention.

A written action plan should be introduced by or with the caregiver(s) managing the asthma (ie, physician or health care professional) and be reviewed at each visit. Individual 
physicians and health care administrators should identify strategies to increase accessibility to education and the use of action plans. One strategy is to formally integrate certified asthma or respiratory educators, who have specialized skills in patient education and self-management, into the health care team. Another strategy is to adapt the action plan for use by different health care providers in a variety of settings.

\section{PHARMACOTHERAPY}

\section{Reliever therapy}

All individuals with asthma should have access to a fast-acting bronchodilator for use as needed to treat acute symptoms. Inhaled fast-acting beta 2 -agonists (FABAs) are the preferred route and class of reliever medication. In Canada, several short-acting beta ${ }_{2}$-agonists (SABAs; eg, salbutamol, terbutaline and fenoterol) and one long-acting beta 2 -agonist (LABA; eg, formoterol) are approved for this indication. Given the possible risks associated with LABA use in the absence of ICS, formoterol should only be used as a reliever in individuals on regular ICS therapy in adults and children 12 years of age and over, preferably in the same inhaler device (ie, combination budesonide/formoterol preparation), instead of two separate inhalers.

Because regular, frequent use of SABAs is associated with increased tolerance, airway sensitivity, and possible increased morbidity and mortality from asthma, they should only be taken on an as needed basis for symptom relief. In doing so, the frequency of reliever use may be used to monitor asthma control. There is no need to use FABAs routinely before an ICS. Regular controller therapy is indicated for children and adults to achieve control when reliever use to relieve daytime asthma symptoms is four or more doses per week, or once or more per week to relieve nighttime symptoms.

Short-acting anticholinergic bronchodilators, such as ipratropium bromide, are considered to be second-line relievers for adults because they are not as effective as FABAs. They are not recommended to be used as relievers in mild to moderate exacerbations in children in or outside of the emergency department setting. They may be useful in the minority of patients who experience side effects with FABAs.

\section{Controller therapy}

Initiation of regular controller therapy is indicated for children six years of age and over, and adults who have one or more indicators of poor control (Table 2). Pharmacological therapy should be determined based on an individual's current asthma control, escalated if needed to gain control, only after addressing other reasons for poor control, and reduced to the least amount required to maintain asthma control. Prescribed controller therapy should take into account both current control and future risk for severe exacerbations.

ICS: After nearly four decades of clinical experience, ICS remain the cornerstone of chronic maintenance asthma pharmacotherapy. There is robust evidence confirming that ICS therapy is effective at reducing asthma symptoms, improving health-related quality of life, improving lung function, decreasing airway hyper-responsiveness, controlling airway inflammation, reducing the frequency and severity of exacerbations, and reducing asthma mortality. Most patients can achieve asthma control by using relatively low doses of ICS, which will produce
TABLE 3

\section{Components of an asthma education program}

1. Written action plan: Provision and explanation of a written action plan comprising:

- How and how often to assess asthma control (self-monitoring)

- Instructions to maintain good control using controller medication and making specific environmental changes

- Signs and symptoms indicating uncontrolled asthma, with instructions on what to do during loss of control (medication to add or increase, how much and how long; when and how to seek additional help (eg, when to go to the hospital or call the health care provider)

2. What is asthma?: A chronic inflammatory condition in which airways are hyper-reactive (sensitive) to environmental (allergenic, irritants or infectious) and/or intrinsic factors

3. Asthma control for all patients: Asthma can be controlled and all patients with asthma can lead a normal life. Regular symptoms and asthma exacerbations indicate treatment failure

4. Reliever versus controller: The difference between reliever and controller medications and their use in the written action plan

5. Identify triggers: Identification and avoidance of environmental triggers specific to the patients

6. Inhaler technique: Teaching and verification of the inhalation technique specific to the inhalation devices prescribed for the patient

7. Medication safety and side effects: Expected onset of action and potential side effects of medications

maximum or near maximum clinical benefit, with minimal risk of long-term adverse effects. The dosing categories for ICS are presented in Table 4. It should be noted that the dose equivalencies listed are approximate and based on efficacy data. The categories, although based on manufacturers' recommendations, are somewhat arbitrary and should be the topic of future systematic review. Hydrofluoroalkane (HFA) beclomethasone was chosen as the reference ICS, because chlorofluorocarbon beclomethasone is no longer available in Canada and the dosing categories approximate those of fluticasone.

Low-dose ICS therapy is recommended for children six years of age and over (less than $200 \mathrm{mcg} /$ day HFA beclomethasone equivalent) and adults with newly diagnosed asthma ( $250 \mathrm{mcg} /$ day or less HFA beclomethasone equivalent), including ICS-naive patients with mild loss of control. In children six years of age and over, and adults presenting with an asthma exacerbation requiring a short course of systemic steroids, daily low- or moderate-dose ICS should be initiated as maintenance long-term therapy.

Failure to demonstrate a clinical response to ICS therapy often relates to one of five factors: erroneous diagnosis of asthma, poor inhaler device technique, poor adherence to maintenance ICS treatment, ongoing exposure to environmental triggers and comorbidities. Unrecognized, these factors often result in many patients being treated inappropriately with higher doses of ICS. If low-dose ICS are not adequate to achieve or maintain asthma control after having addressed these factors, then escalation of ICS to the moderate dose range $(200 \mathrm{mcg} / \mathrm{day}$ to $400 \mathrm{mcg} /$ day HFA beclomethasone equivalent) is the preferred approach in children six years of age and over. However, in adults, this approach often provides little added clinical benefit and increases the risk of potential adverse effects. Consequently, in individuals 12 years of age 
TABLE 4

Inhaled corticosteroid (ICS) dosing categories in children and adults

\begin{tabular}{|c|c|c|c|c|c|c|c|}
\hline \multirow[b]{3}{*}{ Corticosteroid } & \multirow[b]{3}{*}{ Trade name } & \multicolumn{6}{|c|}{ Daily ICS dose, $\mathrm{mcg}$} \\
\hline & & \multicolumn{3}{|c|}{ Children (6 to 11 years of age) } & \multicolumn{3}{|c|}{ Adults (12 years of age and over) } \\
\hline & & Low & Medium & High & Low & Medium & High \\
\hline Beclomethasone dipropionate HFA & QVAR $^{\dagger}$ & $\leq 200$ & $201-400$ & $>400$ & $\leq 250$ & $251-500$ & $>500$ \\
\hline Budesonide* & Pulmicort Turbuhaler ${ }^{\ddagger}$ & $\leq 400$ & $401-800$ & $>800$ & $\leq 400$ & $401-800$ & $>800$ \\
\hline Ciclesonide* $^{\star}$ & Alvesco $^{\S}$ & $\leq 200$ & $201-400$ & $>400$ & $\leq 200$ & $201-400$ & $>400$ \\
\hline Fluticasone & $\begin{array}{l}\text { Flovent MDI and spacer; } \\
\text { Flovent Diskus }\end{array}$ & $\leq 200$ & $201-500$ & $>500$ & $\leq 250$ & $251-500$ & $>500$ \\
\hline
\end{tabular}

Note: Dose equivalencies are approximate and are based on efficacy data. Categories are somewhat arbitrary but are based on manufacturers' recommendations. *Licensed for once daily dosing in Canada; ${ }^{\dagger}$ Graceway Pharmaceuticals Canada; ${ }^{\ddagger}$ AstraZeneca Inc, Canada; ${ }^{\S} \mathrm{Nycomed}$ Canada Inc, Canada; ${ }^{I}$ GlaxoSmithKline Inc, Canada. HFA Hydrofluoroalkane; mcg micrograms; MDI Metered dose inhaler.

and over, add-on therapy (discussed below) should be considered before prescribing doses above $250 \mathrm{mcg} /$ day HFA beclomethasone equivalent, and certainly before prescribing doses above $500 \mathrm{mcg} /$ day HFA beclomethasone equivalent.

While the systemic adverse effects of ICS are not an issue in adults at doses of $250 \mathrm{mcg} /$ day HFA beclomethasone equivalent, it should be recognized that long-term, high doses of ICS can cause both local and systemic adverse effects. At doses above $500 \mathrm{mcg} /$ day HFA beclomethasone equivalent, local side effects become more frequent and may include oropharyngeal candidiasis, dysphonia and, occasionally, coughing from upper airway irritation. For pressurized metered-dose inhalers (MDIs), this risk may be reduced by the use of spacer devices and by mouth rinsing after inhalation. The use of prodrugs that are activated in the lungs, but not in the pharynx (eg, ciclesonide), and new formulations and devices that reduce oropharyngeal deposition, may minimize such effects without the need for a spacer or mouth washing.

ICS have been clearly shown to decrease growth velocity in children (27-29). Growth suppression is an ICS class effect that is likely dose-dependent and, therefore, the lowest effective dose should always be sought. There is some evidence that final height is not affected by ICS use for asthma during childhood $(30,31)$.

Once asthma control has been achieved, it is reasonable to consider reducing the dose of ICS to the lowest level that maintains optimal asthma control. It is important to note that ICS use does not 'cure' asthma. Thus, long-term use for one to two years should be considered before a trial without ICS. When ICS are discontinued, deterioration of clinical control follows within weeks to months in the majority of patients, highlighting the need for follow-up to review control for at least three to six months after discontinuation.

ICS and LABA in combination: A thorough review of treatment adherence to ICS inhalers, environmental factors, comorbidities and inhaler technique should be undertaken before therapy is escalated. When adherence to a low dose of ICS in adults ( $250 \mathrm{mcg} /$ day or less of HFA beclomethasone) or moderate dose of ICS in children six years of age and over $(200 \mathrm{mcg} / \mathrm{day}$ to $400 \mathrm{mcg} /$ day of HFA beclomethasone), together with trigger avoidance and education are insufficient to control asthma symptoms, then a combination inhaler containing both an ICS and a LABA (eg, fluticasone plus salmeterol or budesonide plus formoterol) is the preferred treatment option. Although there is no convincing difference in the efficacy of administering ICS and LABA in the same or separate inhalers, combination inhalers are preferred because they preclude use of the LABA without an ICS, are more convenient and may enhance adherence. LABAs should never be prescribed as monotherapy in asthma (ie, without also prescribing an ICS), because they do not have sufficient anti-inflammatory properties when used alone. When used without ICS, LABAs have been associated with an increased risk of death and hospitalization $(32,33)$. Current evidence does not support the routine use of ICS and LABAs together as initial therapy in steroid-naive adults or children $(34,35)$. The combination of budesonide plus formoterol is approved for use in Canada as a single inhaler for maintenance and reliever therapy in individuals 12 years of age and over and, therefore, is an option in that age group when control is not achieved with ICS monotherapy.

Leukotriene receptor antagonists: Antileukotrienes are a class of anti-inflammatory drugs that interfere either with leukotriene production (eg, 5-lipoxygenase inhibitors) or with leukotriene receptors (eg, leukotriene receptor antagonists [LTRAs]). In Canada, two LTRAs are available: zafirlukast, licensed for use at a dose of $20 \mathrm{mg}$ twice daily $(1 \mathrm{~h}$ before meals or $2 \mathrm{~h}$ after meals) in patients aged 12 years of age and over; and montelukast, licensed for use once daily ( $5 \mathrm{mg}$ for five- to 14 -year-olds; $10 \mathrm{mg}$ for 15 years of age and over).

Current evidence demonstrates that monotherapy with low doses of ICS ( $200 \mathrm{mcg}$ to $250 \mathrm{mcg}$ of HFA beclomethasone equivalent) are more effective than LTRAs alone in the management of persistent asthma, especially in reducing the risk of exacerbations (36). The evidence is stronger in adults than in children, in whom the few head-to-head comparisons have been performed.

Regarding add-on therapy to ICS, the addition of a LABA has been studied more extensively and, in general, has been found to be superior to adding LTRAs in adults (37). Although the combination of an ICS and a LABA is more effective for improving lung function, its superiority for improving symptoms, reducing the use of rescue beta ${ }_{2}$-agonists, and preventing exacerbations remains modest compared with the combination of ICS and LTRA. In contrast to adults, there are no published head-to-head comparisons between LABAs and LTRAs as add-on to ICS for children. In children six to 11 years of age, the addition of a LABA to an ICS in a fixed-dose regimen has not been shown to be of more value than a moderate dose of ICS alone (38).

LTRAs are acceptable, second-line daily monotherapy for children six years of age and over, and adults (39); for example, if adherence to ICS therapy is unsatisfactory, if the ICS dose 
required to maintain control is very low $(100 \mathrm{mcg} /$ day or less of HFA beclomethasone equivalent) or if the patient also has mild allergic rhinitis. As add-on therapy to ICS in adults, LTRAs are a third-line option for asthma that is not satisfactorily controlled with the combination of low-dose ICS and a LABA (38).

As add-on therapy to ICS in children six years of age and over, the addition of either a LABA or LTRA are second-line options in lieu of increasing the ICS to a moderate dose (40). Given the effects of higher doses of ICS on growth in children (27-29), and the general side effects in adults, the ICS dose should be reduced to the minimal effective dose when control has been achieved.

Prednisone: Systemic corticosteroids have two important roles in the management of asthma: as part of the treatment of moderate to severe acute exacerbations, and the chronic management of difficult to control asthma (also termed 'refractory' asthma) (41-43). For exacerbations, a short course of oral prednisone $(1 \mathrm{mg} / \mathrm{kg}$ to $2 \mathrm{mg} / \mathrm{kg}$ for three to five days in children and $40 \mathrm{mg}$ to $60 \mathrm{mg}$ for seven to 14 days in adults) is effective. Intravenous corticosteroids are not routinely required and, assuming the patient is on maintenance ICS, the oral dose need not be tapered. Intravenous or intramuscular routes of administration are warranted if poor oral absorption or poor adherence are issues; however, side effects are common with the intramuscular route. While chronic oral steroid therapy may be effective for difficult to control asthma, such use should be avoided in all age groups if at all possible, particularly children, due to adverse effects. Factors contributing to poor control (Figure 1) should always be sought and remedied, whenever possible, to obviate or minimize the need for chronic systemic steroid use. If long-term oral corticosteroids are required, the issue of osteoporosis prevention should be addressed.

Anti-immunoglobulin E: Omalizumab is currently the only antiimmunoglobulin (Ig) E monoclonal antibody therapy approved by Health Canada for the treatment of moderate to severe, persistent allergic asthma in adults and children 12 years of age and over. It is not approved for the treatment of allergic rhinitis or other related allergic diseases. Because of the significant cost, omalizumab should only be considered for patients with difficult to control asthma confirmed with objective measures, who have documented allergies to a perennial aeroallergen, a serum IgE level of $30 \mathrm{IU} / \mathrm{mL}$ to $700 \mathrm{IU} / \mathrm{mL}$ and whose asthma symptoms remain uncontrolled despite adherence to high-dose ICS plus at least one additional controller therapy. It is administered subcutaneously once or twice per month, depending on the patient's body weight and serum IgE level. It should be prescribed as part of a well-controlled therapeutic trial (ideally of 14 weeks) supervised by an asthma specialist to ensure adequate environmental control and adherence to current anti-inflammatory therapies. A patient's response to anti- $\operatorname{lgE}$ therapy should be regularly reviewed because not all patients respond to this therapy.

Theophylline compounds: Sustained-release theophylline compounds should only be used as third- or fourth-line controller therapy after ICS, LABAs and/or LTRAs. Because of their narrow toxic/therapeutic ratio and frequent side effects, theophylline compounds should only be prescribed by specialists who are familiar with managing difficult to control asthma. If used for maintenance therapy, the $24 \mathrm{~h}$ products are best taken with the supper meal and peak levels monitored for toxicity.

\section{REGULAR REASSESSMENT TO ACHIEVE AND MAINTAIN CONTROL}

Asthma control (Table 2), including objective assessment of airflow rates by spirometry or peak expiratory flow meter readings, should be assessed regularly. The main factors affecting asthma control, illustrated in the upper left of the continuum diagram (Figure 1), should be addressed to gain and maintain asthma control before escalating pharmacotherapy, and to enable reduction of maintenance pharmacotherapy to the lowest amount required to maintain control.

\section{Spirometry or PEF}

Objective measurements of lung function should be performed in individuals six years of age and over, not only to confirm the clinical diagnosis, as discussed previously, but also to assess asthma control at each visit. The goal of therapy is to achieve normal or 'near normal' lung function. Symptoms are fairly reliable indexes of asthma control; however, symptoms and lung function do not always correlate. Some patients who are poorly controlled based on objective measures of lung function perceive few, if any, symptoms. Poor perception of asthma symptoms is considered a risk factor for life-threatening asthma (44-46). Changes in symptoms often precede lung function change during loss of control. Spirometry is the preferred objective measure for assessing asthma control for several reasons. Although PEF testing is simpler to perform, it is effortdependent, requires proper training, is not interchangeable with the $\mathrm{FEV}_{1}$ and can underestimate airway obstruction. Nonetheless, PEF recordings with a portable peak flow meter are an acceptable alternative when spirometry is not available. Most patients do not need to monitor their PEF routinely, but home or office PEF monitoring may be helpful in poor perceivers of asthma symptoms, particularly as part of a written action plan and for evaluation of suspected work-related asthma. Caution is required when interpreting PEF values because data in diaries often represent forgery or best estimates of the patient. These data may misdirect therapy and treatment decisions and should not be based solely on these recordings unless electronic PEF meters are used (47).

\section{Triggers}

Patients with asthma should avoid triggers of asthma as much as possible. This is particularly important for allergens to which the patient is sensitized. In addition, mainstream and second-hand cigarette smoke should be avoided because of irritant effects and because they reduce a patient's response to ICS. Triggers at work may include perfumes and air fresheners, and workplace respiratory regulations should be encouraged. Respiratory (particularly viral) infections are common triggers of loss of asthma control and exacerbations. In a subset of asthma patients, acetylsalicylic acid and other nonsteroidal anti-inflammatory agents may provoke severe asthma exacerbations, especially in patients with nasal polyps. Some food additives such as sulphites and monosodium glutamate may also trigger asthma symptoms. Cold air, exercise, smoke and fumes, pollutants and emotional stress can also induce asthma symptoms depending on the degree of the individual's airway hyper-responsiveness. Women with asthma may 
also experience worsening of their asthma symptoms in the premenstrual period. During the assessment of any adult with asthma, the diagnosis of occupational asthma should be suspected. Sensitizers at the workplace (eg, paint, wood products, flour, etc) should be identified as potential causal agents of adult-onset and occupational asthma.

\section{Inhaler technique}

The preferred method of medication delivery for asthma is by inhalation, which enables the direct deposition of medication to the affected airways, leading to better efficiency and fewer side effects. While there are a number of different devices available, the most used is the pressurized $\mathrm{MDI}$, which requires proper technique:

\section{Shake the MDI;}

2. Breath out to the end of a normal breath;

3. Actuate through an open mouth, just after inhalation begins;

4. Breath in slowly over $4 \mathrm{~s}$ to $6 \mathrm{~s}$, to full lung volume;

5. Hold breath $5 \mathrm{~s}$ to $10 \mathrm{~s}$; and

6. Wait $30 \mathrm{~s}$ to $60 \mathrm{~s}$, shake and repeat above steps.

This takes practice and some of the newer devices have made it easier when mistakes are made. The addition of a holding chamber (spacer device) with mouthpiece is helpful in overcoming poor hand-mouth coordination and reducing side effects, with increased drug delivery and lung deposition. Holding chambers with facemask attachments are useful for the elderly, who can use four to six tidal breaths for each actuation of the medicine. The use of nebulized aerosol medication is not routinely indicated for home management because it is more expensive and may have more side effects. Dry powder inhaler (DPI) devices are generally easier to use because they are breath-actuated and require only one proper inhalation to deliver the desired dose; however, they require a minimal inhaled flow rate. Children six years of age and over can achieve the minimal required inhaled flow rate, but adequacy of technique should be tested before initiating DPIs in children, particularly when switching from an MDI technique. Unlike the MDI, the faster the inhalation from a DPI, the more medicine is delivered. The newer DPIs are, however, less flow-dependent. Regardless of the delivery device chosen, patients must be taught and encouraged to practice the correct technique, and device technique should be reassessed and reinforced periodically (some suggest at every visit). Illustrations of how to teach proper inhalation device use are available on the Ontario Lung Association's Provider Education Program web site (http://www.on.lung.ca/Health-Care-Professionals/ Provider-Education-Program/CD-ROMS.php).

\footnotetext{
Adherence

As with other chronic diseases, good health outcomes in asthma depend on adherence to evidence-based management. A strong foundation for patient adherence is constructed with an accurate diagnosis that is accepted by the patient, an understanding of asthma as a chronic disease requiring long-term treatment, and an understanding of the role of maintenance and reliever therapy. Adherence is enhanced with an acceptance of the safety of prescribed medications and a treatment strategy that is easily understood (ie, simple to do with few medications taken less frequently, etc). Adherence to asthma
}

therapy and the level of asthma control achieved reflects the behaviours of both the health care professionals and patients (48). Adherence at the clinical level can be explored in a nonjudgmental way by acknowledging that incomplete observance is common and then using the patient's use pattern to revise a treatment plan (5). Physician-patient partnerships that include individuals as managers of their own health care may enhance adherence. This type of partnership is extended to include certified asthma and respiratory educators where resources permit (See the Canadian Network for Asthma Care's web site for training and certification details [www.cnac.net]). Health care providers should explore barriers to adherence at each visit. These may include cost of drugs, timing of administration, beliefs of noneffectiveness, concern regarding side effects and forgetfulness. Providers should ensure that patients comprehend the name, purpose, duration of treatment, dosing schedule and expected adverse effects of each asthma medication. Current techniques to improve adherence for chronic diseases are complex and often ineffective (49). Thus, more research is needed to find the best methods to assist patients in adhering to medical regimens.

\section{Comorbidities}

Comorbidities are common in older adults with asthma (50). Rhinitis and sinusitis are common causes of poor control that merit treatment. This can be best achieved with incremental therapy including antihistamines and/or topical nasal corticosteroids. While the standards of care remain ICS and intranasal corticosteroids, leukotriene modifier therapy is a potential alternative in patients with both easily controlled asthma and mild rhinitis. Gastroesophageal reflux disease (GERD) has been increasingly identified in patients with asthma (51); however, there is strong evidence confirming that empirical treatment of reflux in asthma is not warranted (52). In asthma patients with symptomatic GERD, the evidence for treatment is inconclusive; however, one large study (52) demonstrated a lower risk of asthma exacerbations in patients with symptomatic GERD who received GERD treatment. Treatment should be initiated based on the severity of GERD and not in anticipation that its elimination will consistently improve asthma control.

The impact of obesity on asthma control is controversial. Increasing evidence suggests that obesity makes asthma more difficult to control $(50,53)$. Although there has been concern that obesity may be associated with an overdiagnosis of asthma, this has been shown to be a problem common to both obese and nonobese adults (7). Weight loss should be encouraged in patients with asthma who are obese. Moreover, weight loss will likely improve the patients' general well-being and also contribute to better asthma control $(54,55)$.

\section{SUMMARY OF KEY DIFFERENCES BETWEEN PEDIATRIC AND ADULT ASTHMA MANAGEMENT}

Important differences in the management and monitoring of children and adults with asthma merit specific emphasis.

\section{Medication differences}

- High doses of ICS (Table 4) may be associated with significant side effects in children, including growth 
suppression, and should only be used by asthma specialists. Most children will achieve control with low doses of ICS, which are not associated with clinically significant growth suppression. Failure to rapidly achieve control with moderate doses of ICS should prompt referral to a specialist.

- If low-dose ICS are not adequate to maintain asthma control in children six to 11 years of age, a moderate dose of ICS should be initiated. The preferred therapy escalation in children 12 years of age and over, and in adults is the addition of a LABA to the low-dose ICS, in the form of a combination inhaler.

- The preferred second-line therapy in children whose asthma is not controlled on moderate dose of ICS is the addition of a either a LABA or LTRA.

- The use of a single inhaler therapy combination of budesonide and formoterol is not approved in children younger than 12 years of age.

- The choice of inhalation devices varies with age. Children six years of age and over should be able to use a holding chamber with a mouthpiece. Children six years of age and over may be assessed for using a DPI, or may continue with an MDI with holding chamber and mouthpiece, similar to adults. Nebulizers should not be used as a first-line treatment in children or adults.

\section{Monitoring differences}

- Growth in children should be carefully monitored by measuring height and weight at each follow-up asthma visit and plotting these measurements on a growth curve. A falloff in growth should prompt referral to a specialist.

\section{REFERENCES}

1. Lemiere C, Bai T, Balter M, et al. Adult Asthma Consensus Guidelines Update 2003. Can Respir J 2004;11(Suppl A):9A-18A.

2. Becker A, Berube D, Chad Z, et al. Canadian Pediatric Asthma Consensus guidelines, 2003 (updated to December 2004): Introduction. CMAJ 2005;173(6 Suppl):S12-S14.

3. Expert Panel Report 3 (EPR 3): Guidelines for the Diagnosis and Management of Asthma. 2007. Bethseda, Maryland, National Heart, Lung, and Blood Institute, National Institutes of Health, No. 08-4051 (prepublication copy).

4. British Guideline on the Management of Asthma: A national clinical guideline. Scottish Intercollegiate Guidelines Network (SIGN); British Thoracic Society; 2008.

5. Global Initiative for Asthma (GINA). Global Strategy for Asthma Management and Prevention, 2008. <http://www.ginasthma.com/ GuidelinesResources.asp?11=2\&12=0>

(Accessed November, 2009)

6. Global Initiative for Asthma (GINA). Global Strategy for the Diagnosis and Management of Asthma in Children 5 Years and Younger, $2009<\mathrm{http} / /$ www.ginasthma.com/GuidelinesResources. asp?l1 $=2 \& 12=0>$ (Accessed November, 2009).

7. Aaron SD, Vandemheen KL, Boulet LP, et al. Overdiagnosis of asthma in obese and nonobese adults. CMAJ 200818;179:1121-31.

8. Miller MR, Hankinson J, Brusasco V, et al. Standardisation of spirometry. Eur Respir J 2005;26:319-38.

9. Reddel HK, Taylor DR, Bateman ED, et al. An official American Thoracic Society/European Respiratory Society statement: Asthma control and exacerbations: Standardizing endpoints for clinical asthma trials and clinical practice. Am J Respir Crit Care Med 2009;180:59-99.

10. Ernst P, FitzGerald JM, Spier S. Canadian Asthma Consensus Conference Summary of Recommendations. Can Respir J 1996;3:89-100.

11. Global Initiative for Asthma (GINA). Global Strategy for Asthma Management and Prevention. Global Initiative for Asthma (GINA); 2007.
- In young children, questions about exercise-induced asthma should be directed to play time (eg, Does your child cough when running around during play, or when laughing or crying?).

- Education must be given to the parent-child dyad/triad for young children and shift to the child as they approach adolescence.

ACKNOWLEDGEMENTS: The authors thank Canadian Lung Association staff Ms Janet Sutherland for her outstanding administrative support. Dr FitzGerald is a Michael Smith Foundation for Health Research Distinguished Scholar. Dr Rowe is supported by a 21st Century Canada Research Chair in Emergency Airway Diseases from the Government of Canada (Ottawa, Ontario).

SPONSORING ORGANIZATIONS: Canadian Thoracic Society and The Lung Association.

FUNDING: The Canadian Thoracic Society received unrestricted grants to facilitate the knowledge translation activities of the CTS Asthma Committee from AstraZeneca Canada, GlaxoSmithKline Inc, Canada, Merck Frosst Canada and Novartis Pharmaceuticals Canada Inc. None of the sponsors played a role in the collection, review, analysis or interpretation of the scientific literature or in any decisions regarding the key messages presented in this document.

DISCLOSURE OF COMPETING INTERESTS: Collectively, the physicians on the CTS Asthma Committee have on at least one occasion acted as consultants for, received research funds from, and received speaker's fees from these pharmaceutical companies.

12. Sama SR, Milton DK, Hunt PR, Houseman EA, Henneberger PK, Rosiello RA. Case-by-case assessment of adult-onset asthma attributable to occupational exposures among members of a health maintenance organization. J Occup Environ Med 2006;48:400-7.

13. Balmes J, Becklake M, Blanc P, et al. American Thoracic Society Statement: Occupational contribution to the burden of airway disease. Am J Respir Crit Care Med 2003;167:787-97.

14. Blanc PD, Toren K. How much adult asthma can be attributed to occupational factors? Am J Med 1999;107:580-7.

15. Tarlo SM, Balmes J, Balkissoon R, et al. Diagnosis and management of work-related asthma: American College Of Chest Physicians Consensus Statement. Chest 2008;134(3 Suppl):1S-41S.

16. Sheffer AL. Allergen Avoidance to Reduce Asthma-Related Morbidity. New Engl J Med 2004;351:1134-6.

17. Krieger JW, Takaro TK, Song L, Weaver M. The Seattle-King County Healthy Homes Project: A randomized, controlled trial of a community health worker intervention to decrease exposure to indoor asthma triggers. AJPH 2005;95:652-9.

18. O'Connor GT. Allergen avoidance in asthma: What do we do now? J Allergy Clin Immunol 2005;116:26-30.

19. Dijkstra A, Vonk JM, Jongepier $\mathrm{H}$, et al. Lung function decline in asthma: Association with inhaled corticosteroids, smoking and sex. Thorax 2006;61:105-10.

20. Thomson NC, Chaudhuri R. Asthma in smokers: Challenges and opportunities. Curr Opin Pulm Med 2009;15:39-45.

21. Steib DM, Szyszkowicz M, Rowe BH, Leech JA. Air pollution and emergency department visits for cardiac and respiratory conditons: A multi-city time-series analysis. Environ Health 2009;8:25.

22. Burra TA, Moineddin R, Agha MM, Glazier RH. Social disadvantage, air pollution, and asthma physician visits in Toronto, Canada. Environ Res 2009;109:567-74.

23. Toelle BG, Ram FS. Written individualised management plans for asthma in children and adults. Cochrane Database Syst Rev 2004:CD002171. 
24. Gibson PG, Powell H, Coughlan J, et al. Self-management education and regular practitioner review for adults with asthma. Cochrane Database Syst Rev 2003:CD001117.

25. Powell H, Gibson PG. Options for self-management education for adults with asthma. Cochrane Database Syst Rev 2003:CD004107.

26. Zemek RL, Bhogal SK, Ducharme FM. Systematic review of randomized controlled trials examining written action plans in children: What is the plan? Arch Pediatr Adolesc Med 2008;162:157-63.

27. Sharek PJ, Bergman DA. Beclomethasone for asthma in children: Effects on linear growth. Cochrane Database Syst Rev 2000:CD001282.

28. Sharek PJ, Bergman DA. The effect of inhaled steroids on the linear growth of children with asthma: A meta-analysis. Pediatrics 2000;106:E8.

29. Agertoft L, Pedersen S. Effect of long-term treatment with inhaled budesonide on adult height in children with asthma. N Engl J Med 2000;343:1064-9.

30. Long-term effects of budesonide or nedocromil in children with asthma. The Childhood Asthma Management Program Research Group. N Engl J Med 2000;343:1054-63.

31. Doull IJ. The effect of asthma and its treatment on growth. Arch Dis Child 2004;89:60-3.

32. Salpeter SR, Buckley NS, Ormiston TM, Salpeter EE. Metaanalysis: Effect of long-acting beta-agonists on severe asthma exacerbations and asthma-related deaths. Ann Intern Med 2006;144:904-12.

33. Ernst P, McIvor A, Ducharme FM, et al. Safety and effectiveness of long-acting inhaled beta-agonist bronchodilators when taken with inhaled corticosteroids. Ann Intern Med 2006;145:692-4.

34. Lemiere C, Becker A, Boulet LP, et al. Should combination therapy with inhaled corticosteroids and long-acting $\beta_{2}$-agonists be prescribed as initial maintenance treatment for asthma? CMAJ 2002;167:1008-9.

35. Ni Chroinin M, Greenstone I, Lasserson TJ, Ducharme FM. Addition of inhaled long-acting beta2-agonists to inhaled steroids as first line therapy for persistent asthma in steroid-naive adults and children. Cochrane Database Syst Rev 2009:CD005307.

36. Ducharme FM, Hicks GC. Anti-leukotriene agents compared to inhaled corticosteroids in the management of recurrent and/or chronic asthma in adults and children. Cochrane Database Syst Rev 2002:CD002314.

37. Ducharme FM, Lasserson TJ, Cates CJ. Long-acting beta2-agonists versus anti-leukotrienes as add-on therapy to inhaled corticosteroids for chronic asthma. Cochrane Database Syst Rev 2006;4:CD003137.

38. Ni Chroinin M, Lasserson TJ, Greenstone I, Ducharme FM. Addition of long-acting beta-agonists to inhaled corticosteroids for chronic asthma in children. Cochrane Database Syst Rev 2009;3:CD007949.

39. Ducharme FM, Hicks GC. Anti-leukotriene agents compared to inhaled corticosteroids in the management of recurrent and/or chronic asthma in adults and children. Cochrane Database Syst Rev 2004;2:CD002314.

40. Ducharme FM, Schwartz Z, Kakuma R. Addition of anti-leukotriene agents to inhaled corticosteroids for chronic asthma. Cochrane Database Syst Rev 2004;1:CD003133.

41. Chung KF, Godard P, Adelroth E, et al. Difficult/therapyresistant asthma: The need for an integrated approach to define clinical phenotypes, evaluate risk factors, understand pathophysiology and find novel therapies. ERS Task Force on Difficult/Therapy-Resistant Asthma. European Respiratory Society. Eur Respir J 1999;13:1198-208.

42. Proceedings of the ATS workshop on refractory asthma: Current understanding, recommendations, and unanswered questions. American Thoracic Society. Am J Respir Crit Care Med 2000;162:2341-51.

43. Wenzel S. Severe asthma in adults. Amer J Respir Crit Care Med 2005;172:149-60.

44. Rubinfeld AR, Pain MCF. Perception of asthma. Lancet 1976;1:882-4.

45. Kikuchi Y, Okabe S, Tamaura G, et al. Chemosensitivity and perception of dyspnea in patients with a history of near-fatal asthma. N Engl J Med 1994;330:1329-34.

46. Magadle R, Berar-Yanay N, Weiner P. The risk of hospitalization and near-fatal and fatal asthma in relation to the perception of dyspnea. Chest 2002;121:329-33.

47. Kamps AW, Roorda RJ, Brand PL. Peak flow diaries in childhood asthma are unreliable. Thorax 2001;56:180-2.

48. Horne R, Price D, Cleland J, et al. Can asthma control be improved by understanding the patient's perspective? BMC Pulm Med 2007;7:8

49. Haynes RB, Montague P, Oliver T, McKibbon KA, Brouwers MC, Kanani R. Interventions for helping patients to follow prescriptions for medications. Cochrane Database Syst Rev 2002;2:CD000011.

50. Boulet LP. Influence of comorbid conditions on asthma. Eur Respir J 2009;33:897-906.

51. Gibson PG, Henry RL, Coughlan JL. Gastro-oesophageal reflux treatment for asthma in adults and children. Cochrane Database Syst Rev 2003;2:CD001496.

52. Littner MR, Leung FW, Ballard ED, Huang B, Samra NK. Effects of 24 weeks of lansoprazole therapy on asthma symptoms, exacerbations, quality of life, and pulmonary function in adult asthmatic patients with acid reflux symptoms. Chest 2005; 128:1128-35.

53. Lavoie KL, Bacon SL, Labrecque M, Cartier A, Ditto B. Higher $\mathrm{BMI}$ is associated with worse asthma control and quality of life but not asthma severity. Respir Med 2006;100:648-57.

54. Eneli IU, Skybo T, Camargo CA Jr. Weight loss and asthma: A systematic review. Thorax 2008;63:671-6.

55. Stenius-Aarniala B, Poussa T, Kvarnstrom J, Gronlund EL, Ylikahri M, Mustajoki P. Immediate and long term effects of weight reduction in obese people with asthma: Randomised controlled study. BMJ 2000;320:827-32. 


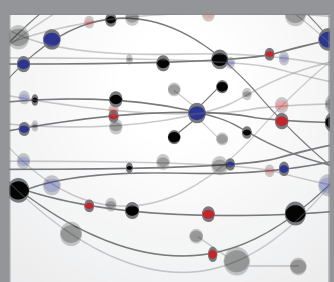

The Scientific World Journal
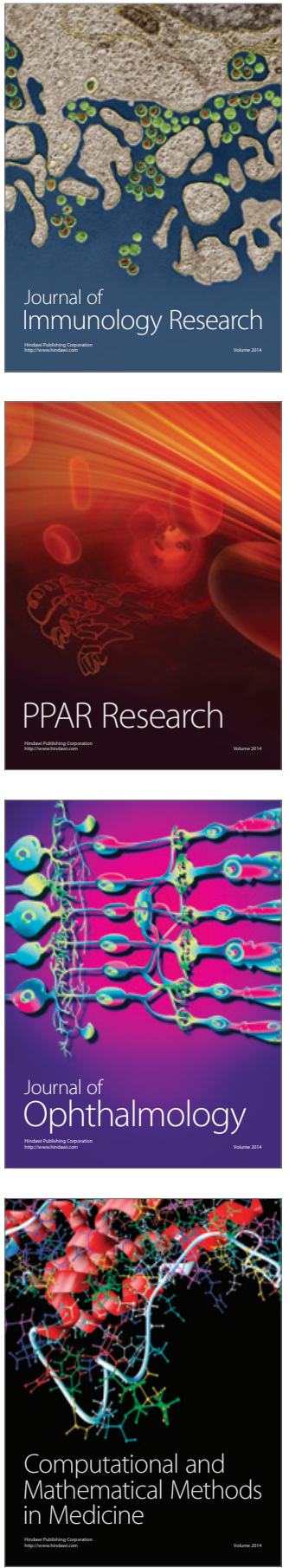

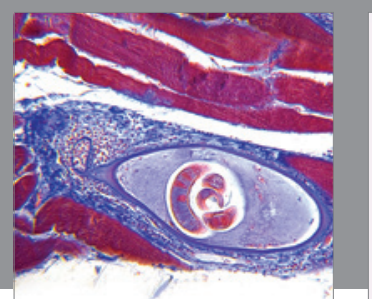

Gastroenterology Research and Practice

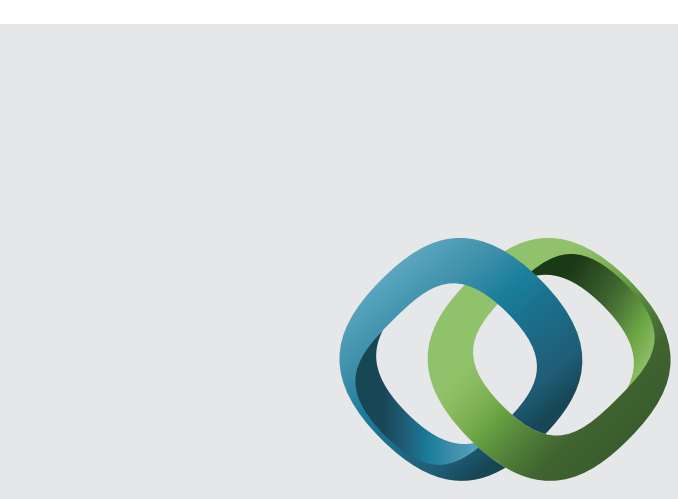

\section{Hindawi}

Submit your manuscripts at

http://www.hindawi.com
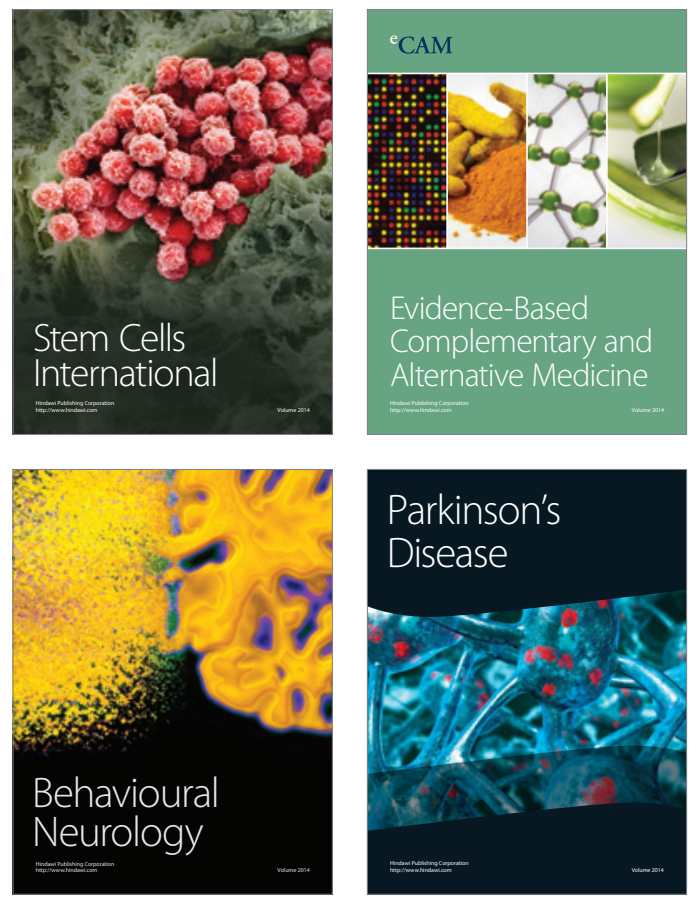
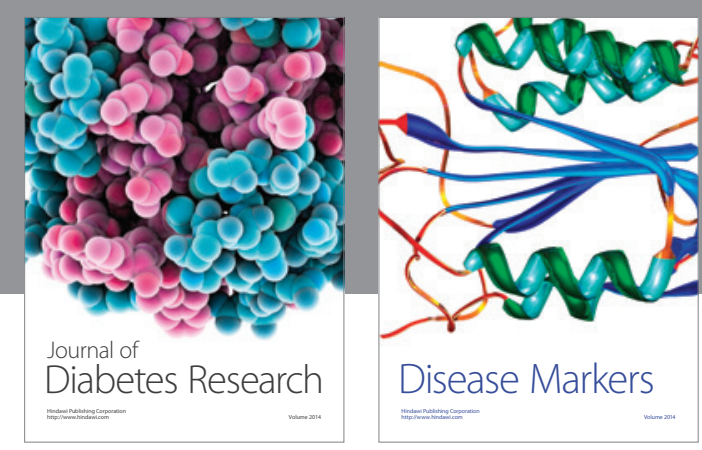

Disease Markers
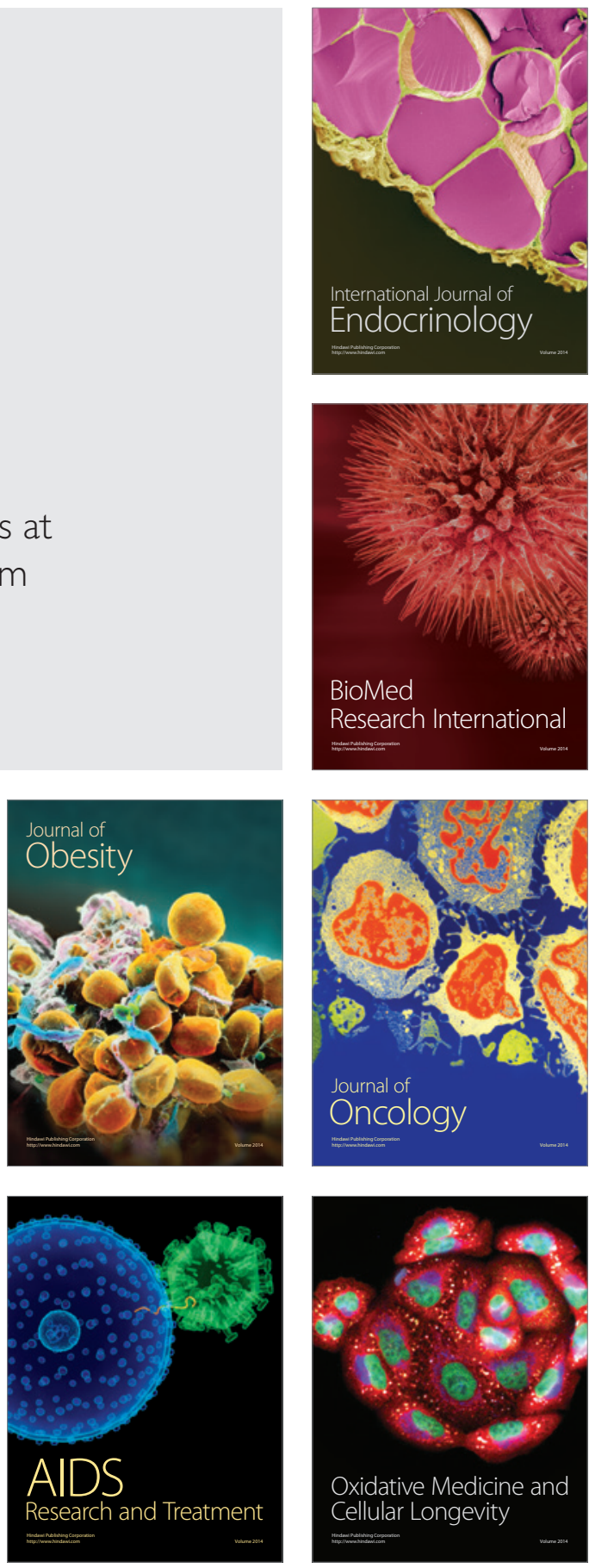